
\title{
25 Research Soure \\ Trachoma in Sudan: Case Series from Two Eye Care Hospitals and a Review of the Literature
}

Rawan Sharaf Eldein Elamein Hassan ( $\nabla$ rawan_455@hotmail.com )

Faculty of Medicine, University of Khartoum https://orcid.org/0000-0003-4164-2678

\section{Mohamed Abdulmonem Salih Aabdeen}

Nile Valley University Faculty of Medicine and Health Sciences

\section{Razan Sharaf Eldein Elamein Hassan}

Alzaiem Alazhari University Faculty of Medicine

\section{Sagad Omer Obeid Mohamed}

University of Khartoum Faculty of Medicine

Fadwa Mohammed Saad

University of Khartoum Faculty of Medicine

Haidar AbuAhmed Mohamed

University of Khartoum Faculty of Medicine

\section{Research Article}

Keywords: Trachoma, clinical stages, socioeconomic status, hygiene, Sudan

Posted Date: July 22nd, 2020

DOl: https://doi.org/10.21203/rs.3.rs-45426/v1

License: (c) (i) This work is licensed under a Creative Commons Attribution 4.0 International License.

Read Full License 


\section{Abstract \\ Background}

Trachoma is a common infectious cause of blindness worldwide. Although it has largely now disappeared from developed countries, it is still endemic in many developing countries. We aimed to highlight clinical stages and common related socio-demographic and household characteristics among patients with trachoma in Sudan.

\section{Methods}

A hospital-based case series descriptive study was conducted at Makah Eye Complex and AbdalfadeelAlmaz hospital in Khartoum, Sudan. We included all Trachoma patients from all age groups attending the two eye care hospitals in the period from 1st to 31st March 2015. Data was collected through clinical examination, hospital records, and face to face interview using a structured questionnaire, Also, we conducted a review of the literature to highlights the epidemiological aspect of trachoma in Sudan, using the databases of MEDLINE (PubMed) and Google Scholar.

\section{Results}

In this case series, we identified 125 patients with trachoma in the study period. Most of them were aged more than 50 years old $(78.4 \%)$. Half of the participants (56\%) were positive for active trachoma, $40.8 \%$ of them were having Trachomatous Trichiasis (TT), and $56 \%$ of them have Trachoma Follicles (TF). Majority of the patients have low socioeconomic status and poor personal and environmental hygiene (88\%), (44\%) and $(74.4 \%)$, respectively.

\section{Conclusion}

Low socioeconomic status and poor personal and environmental hygiene are common sociodemographic and household characteristics among patients with trachoma. Despite the progress that has been made towards disease elimination, trachoma is still a public health problem in Sudan. Our review highlights the magnitude of trachoma and the progress towards its elimination in Sudan.

\section{Background}

Trachoma is a chronic cicatrizing conjunctivitis caused by Chlamydia trachomatis, which leads to progressive scarring of the lids and the cornea [1]. It is considered the leading cause of preventable blindness worldwide for being responsible for more than $3 \%$ of the world's blindness. According to the World Health Organization (WHO), trachoma is endemic in more than 50 countries worldwide and is responsible for the visual impairment of about 1.8 million people, of whom 0.5 million are irreversibly 
blind, representing about $1.4 \%$ of the global total of blind individuals [2-3]. Approximately 232 million people live in trachoma endemic areas and are at risk [2-3].

The disease is largely related to environmental risk factors; the strongest of which is poor hygiene, most likely reflecting poor access to water, latrine use, and lack of sanitation, thus promoting transmission by providing suitable breeding sites for eye-seeking flies [4-5]. Personal risk factors relate to face and hands washing regardless of the distance to the water source [6]. The clinical manifestations of trachoma are subdivided into those with "active" disease, commonly seen in childhood, and those associated with "chronic" complications like Trachomatous Trichiasis (TT) and corneal opacification (CO), usually seen in late childhood and adults [7].

Trachoma has long been known to be prevalent in parts of Sudan and the number of cases of TT in endemic areas is 67,000 patients [8]. Sudan is among the five countries at which half of the global burden of active trachoma is concentrated and among the three countries at which half of the global burden of TT is concentrated [8]. In Sudan, there is paucity in studies that highlight the most common related factors and clinical stages among trachoma patients. With this background, the current study aimed to describe the clinical stages of trachoma and the common presenting socio-demographic and household characteristics among trachoma patients.

\section{Methods}

A descriptive, case series study was carried out from the $1^{\text {st }}$ of March to the $31^{\text {st }}$ of March 2015 in Makah Eye Complex and Abdalfadeel-Almaz hospital, Khartoum state, Sudan. These two settings were chosen because they are the main public healthcare facilities providing specialized clinical ophthalmological services for a great number of the Khartoum state population.

We included all patients with definite clinical signs of trachoma from all age groups according to the World Health Organization (WHO) Trachoma grading system. Structured face to face interviews with patients used to assess socio-demographic and household characteristics, using a structured questionnaire. The main parts were the study population, demographic characteristics and assessment of environmental and personal hygiene. Before filling the questionnaire, all patients who came to the clinic were examined for the presence of trachoma, and once found positive, the patient was referred to the consultant ophthalmologist to prove diagnosis and prescribe the appropriate medication.

Furthermore, we conducted a review of the recent literature to summarize the relevant studies about current epidemiological aspects of trachoma in Sudan, through searching the databases of MEDLINE (PubMed) and Google Scholar, from January 2000 to July 2020.

\section{Ethical consideration and consent}


Permission for conducting this research was granted from the Faculty of Medicine, University of Khartoum before study initiation, and permission was also granted by the general directors of Makah Eye Complex and Abdalfadeel-Almaz hospital, Khartoum, Sudan. Ethical approval was obtained from the State Ministry of Health in Khartoum state, Sudan. Each patient's informed consent was obtained before participation in the study.

\section{Results}

\section{Socio-demographic and household characteristics}

The study included 125 patients with trachoma from two eye care hospitals; 80 patients $(60.4 \%)$ were from Makah eye complex and 45 patients (35.2\%) were from Abdelfadeel-Almaz hospital. There were 68 patients $(54.4 \%)$ females and 57 males $(45.6 \%)$ males. The majority of the participants $(78.4 \%)$ were aged more than 50 years. Most of the respondents (61.6\%) were resident in Khartoum state, and (16.8\%) were from Gezira state. Most of the respondents (81.6\%) were not having an infected person in the family (Table 1).

Regarding drinking water, most of the respondents 98 (78.4\%) had a pipe inside the house, $8 \%(10)$ had a pipe outside the house as a source of water supply. More than half $(59.2 \%)$ of the respondents have animals and $52.2 \%$ of them have them inside their houses. The majority of the respondents $(74.2 \%)$ were having pit latrines as a type of toilet, whereas $2.4 \%$ were not having toilets at all. Most of the respondents $(68.8 \%)$ were washing their faces $2-5$ times per day, and $4.8 \%$ never wash their faces. Regarding hands washing, the majority (54.4\%) were washing their hands $2-5$ times per day (Table 2 ).

\section{Clinical stages of Trachoma}

All patients were examined on slit lamp by the ophthalmologist and the clinical signs of trachoma were graded in accordance with WHO Trachoma Grading System. Most of the respondents (56\%) were found to have trachoma follicles (TF) and $40.8 \%$ of them were having trachomatus trichiasis (TT) (Table 3 ). 
Table 1

Socio-demographic characteristics of the study population attending two eye care hospitals in Khartoum state, March 2015. ( $n=125)$

\begin{tabular}{|c|c|c|c|}
\hline Variable & & No. & Percent \% \\
\hline \multirow[t]{2}{*}{ Hospital } & Makkah eye complex & 80 & $60.4 \%$ \\
\hline & AbdelfadeelAlmaz & 45 & $35.2 \%$ \\
\hline \multirow[t]{2}{*}{ Gender } & Male & 57 & $45.6 \%$ \\
\hline & Female & 68 & $54.4 \%$ \\
\hline \multirow[t]{4}{*}{ Age } & Less than 15 years & 1 & $0.8 \%$ \\
\hline & $15-29$ years old & 7 & $5.6 \%$ \\
\hline & $30-49$ years old & 19 & $15.2 \%$ \\
\hline & More than 50 years & 98 & $78.4 \%$ \\
\hline \multirow[t]{2}{*}{ Residence } & Khartoum state & 77 & $61.6 \%$ \\
\hline & Gezira state & 21 & $16.8 \%$ \\
\hline \multirow[t]{2}{*}{ Infected person in the family } & Present & 102 & $81.6 \%$ \\
\hline & Absent & 23 & $18.4 \%$ \\
\hline \multirow[t]{6}{*}{ Level of education } & Illiterate & 66 & $52.8 \%$ \\
\hline & Khalwa & 22 & $17.6 \%$ \\
\hline & Primary school & 17 & $13.6 \%$ \\
\hline & Secondary school & 11 & $8.8 \%$ \\
\hline & University graduate & 8 & $6.4 \%$ \\
\hline & Post graduate & 1 & $0.8 \%$ \\
\hline \multirow[t]{4}{*}{ Monthly income } & Less than 1000 SDG & 36 & $28.8 \%$ \\
\hline & 1000-2000 SDG & 9 & $7.2 \%$ \\
\hline & More than 2000 SDG & 3 & $2.4 \%$ \\
\hline & Unemployed & 76 & $60.8 \%$ \\
\hline
\end{tabular}


Table 2

Environmental factors and personal hygiene among patients with trachoma attending two eye care hospitals in Khartoum state, March 2015. ( $n=125)$

\begin{tabular}{|llll|}
\hline Variable & & No. & Percent \% \\
\hline Drinking water source & House pipe & 89 & 78.4 \\
& External pipe & 1 & 0.8 \\
& Wells & 6 & 4.8 \\
& Rivers & 2 & 1.6 \\
\hline Place of Animals breeding (if present) & Inside the house & 66 & 86.8 \\
& & & \\
\hline Type of toilets & Inside the residential block & 10 & 13.2 \\
& Flush toilets & 29 & 23.4 \\
& Pit Latrine & 92 & 74.2 \\
& No toilet & 4 & 2.4 \\
\hline Face washing per day & Once & 8 & 6.4 \\
& $2-5$ times & 86 & 68.8 \\
& More than 5 times & 25 & 20 \\
\hline Never & 6 & 4.8 \\
\hline Hands washing per day & Once & 4 & 3.2 \\
& 2-5 times & 68 & 54.4 \\
& More than 5 times & 52 & 41.6 \\
& Never & 1 & 0.8 \\
\hline
\end{tabular}


Table 3

clinical stages of trachoma among patients with

trachoma attending two eye care hospitals in

Khartoum state, March 2015

\begin{tabular}{|lll|}
\hline Clinical stage & No. & Percent \% \\
\hline Trachoma Follicles (TF) & 70 & 56.0 \\
Trachoma Scarring (TS) & 2 & 1.60 \\
Trachoma Trichiasis (TT) & 51 & 40.8 \\
Corneal Opacification (CO) & 2 & 1.60 \\
\hline
\end{tabular}

\section{Characteristics of the studies included in the review}

Our search retrieved records for 93 published articles. Abstract and full texts of the potentially relevant studies were retrieved for screening and studies lacking insufficient data about the outcomes of interest were subsequently omitted. Lastly, a total of nine epidemiological studies published from 2007 to 2020 which met the eligibility criteria were included [9-17]. Main features and summery of the data from the included studies are shown in (Table 4).

Low socioeconomic status and poor personal and environmental hygiene were the common reported socio-demographic and household characteristics among patients with trachoma in all studies. Particular areas in Sudan exhibited higher burden of Trachoma, where prevalence of trachoma was above the WHO thresholds, specifically Gadarif state and all of five Darfur states. The presence of one million SouthSudanese refugees in displacement camps in White Nile state coming from a trachoma hyper-endemic country could impact the progress towards trachoma elimination [14].

In attempts to eliminate trachoma, Sudan National Trachoma Control Program (NTCP) adopted the WHOSAFE strategy; (Surgery for Trichiasis; Antibiotic therapy through mass distribution; Facial cleanliness promotion through health education; and Environmental improvement with sanitation) [17]. Recently, NTCP piloted a TT case-finding approach in some localities to identify patients and provide surgical services free of charge [17]. However, conflicts and security concerns in several endemic areas of Sudan limits the ability of NTCP to reach trachoma elimination in Sudan [11]. 
Table 4

Descriptive summary of the studies included in the review

\begin{tabular}{|c|c|c|c|}
\hline Study & Year & Study setting & Main findings \\
\hline $\begin{array}{l}\text { Rushood } \\
\text { et al [9] }\end{array}$ & 2007 & $\begin{array}{l}\text { Total coverage survey for of all } \\
\text { governmental primary schools } \\
\text { children in Khartoum State. }\end{array}$ & $\begin{array}{l}\quad \text { Out of } 671,119 \text { children screened, } 288 \\
\text { children had active trachoma: } 86.5 \% \text { of } \\
\text { them were from Ummbada locality, where } \\
\text { poverty is widespread. }\end{array}$ \\
\hline \multirow[t]{5}{*}{$\begin{array}{l}\text { Islam et } \\
\text { al. } \\
\text { [10] }\end{array}$} & \multirow[t]{5}{*}{2009} & \multirow{5}{*}{$\begin{array}{l}\text { Local population of Nyala city, } \\
\text { South Darfur state, in the free } \\
\text { medical camps established by } \\
\text { Pakistani Field Hospital. }\end{array}$} & $\begin{array}{l}\text { Out of } 4326 \text { individuals examined } \\
\text { during the medical camps, } 378(8.73 \%) \\
\text { had clinical signs of trachoma. }\end{array}$ \\
\hline & & & $\begin{array}{l}\text { - } \quad 45.5 \% \text { of patients were less than } 20 \\
\text { years of age. }\end{array}$ \\
\hline & & & $\begin{array}{l}\text { Most of patients had poor personal } \\
\text { hygiene and low socioeconomic status with } \\
\text { lack of basic facilities such as proper house, } \\
\text { clean water and covered latrines. }\end{array}$ \\
\hline & & & $\begin{array}{l}\text { TF and TI were observed in } 81.34 \% \\
\text { and } 50.37 \% \text { of patients respectively. }\end{array}$ \\
\hline & & & $\begin{array}{l}\text { TT and CO was observed in } 19.1 \% \\
\text { and } 14.5 \% \text { of patients, respectively. }\end{array}$ \\
\hline \multirow[t]{5}{*}{$\begin{array}{l}\text { Hassan } \\
\text { et al [11] }\end{array}$} & \multirow[t]{5}{*}{2010} & \multirow{5}{*}{$\begin{array}{l}\text { Large population based cross- } \\
\text { sectional survey conducted in } 88 \\
\text { localities across northern states } \\
\text { of Sudan }\end{array}$} & $\begin{array}{l}\text { Out of } 106,697 \text { participants examined, } \\
31,072 \text { patients had TT. }\end{array}$ \\
\hline & & & $\begin{array}{l}\text { Higher prevalence of TF (more than } \\
10 \% \text { ) in three districts: two in Blue Nile State } \\
\text { (Geissan and Kurmuk); and one in Gederaf } \\
\text { State (El Galabat East). }\end{array}$ \\
\hline & & & $\begin{array}{l}\text { Higher prevalence of TT (above the } \\
\text { WHO threshold for community based } \\
\text { intervention of } 1 \% \text { ) in } 20 \text { districts. }\end{array}$ \\
\hline & & & $\begin{array}{l}\quad \text { Prevalence of TT increased } \\
\text { significantly with age and females } \\
\text { compared to males. }\end{array}$ \\
\hline & & & $\begin{array}{l}\text { Factors associated with presence of a } \\
\text { child with trachoma: Increasing household } \\
\text { size, household head with no formal } \\
\text { education, livestock in compound, and pit } \\
\text { latrine }\end{array}$ \\
\hline \multirow[t]{2}{*}{$\begin{array}{l}\text { Elshafie } \\
\text { et al [12] }\end{array}$} & \multirow[t]{2}{*}{2016} & \multirow[t]{2}{*}{$\begin{array}{l}\text { Cross sectional, community- } \\
\text { based survey covering Khartoum } \\
\text { State and all accessible districts } \\
\text { in the five Darfur States }\end{array}$} & $\begin{array}{l}\text { 73,489 residents examined in } 908 \\
\text { villages. The highest prevalence of TF in } \\
\text { children was found in El Fashir district, } \\
\text { North Darfur state }(18.7 \%) \text {. }\end{array}$ \\
\hline & & & $\begin{array}{l}\text { Five districts (El Fashir, Zalinji, Azoom, } \\
\text { Maleet, and El Koma) had TF prevalence } \\
\text { above the WHO threshold (10\%) for mass }\end{array}$ \\
\hline
\end{tabular}


treatment with azithromycin, together with facial cleanliness and environmental improvement interventions.

- $\quad$ TF in children was independently associated with younger age, unimproved sanitation in the household, having $\geq 5$ children in the household, and living in internally displaced persons camps.

$\begin{array}{lll}\text { Alkhidir } 2017 & \begin{array}{l}\text { Population-based prevalence } \\ \text { study of Trachoma among } \\ \text { et al [13] } \\ \text { Galdren in Tabldiya village, } \\ \text { Gadarif State }\end{array}\end{array}$

Sanders 2019 Cross-sectional, multi-stage, et al [14] cluster-random surveys in refugee camps in two localities (Al Salam and Al Jabalain) White Nile State
- $\quad 11.0 \%$ of the 900 participants had active trachoma; $3.96 \%$ of them had TF, and none had TI.

- $\quad$ The prevalence of Chlamydia trachomatis in whole children in the village was $1.4 \%$

- $\quad$ Prevalence of TF in children was $15.7 \%$ in Al Salam and $10.6 \%$ in Al Jabalain.

- $\quad$ Prevalence of TT in those 15 years above was $2.9 \%$ in Al Salam and $5.0 \%$ in Al Jabalain.

- $\quad$ Participants in these two refugee camps reported coming from four states in South Sudan (Upper Nile, Unity, Jonglei, and Western Bahr el Ghazal states).
Macleod 2019 Secondary analysis of data from et al [15]

27 cross-sectional populationbased trachoma prevalence surveys carried out in the internally displaced persons camps in the five Darfur States
- $\quad$ Out of 1926 children examined, 38 (8\%) had TF. Poor sanitation, younger age and living in a household that purchased water from a vendor were associated with TF in children.

- $\quad$ Out of 2139 adults examined, 16 $(0.7 \%)$ had TT. TT was strongly independently associated with being older and living alone.

\begin{tabular}{|c|c|c|}
\hline $\begin{array}{l}\text { Sanders } \\
\text { et al [16] }\end{array}$ & 2019 & $\begin{array}{l}\text { Population-based Trachoma } \\
\text { prevalence surveys in seven } \\
\text { localities across five states of } \\
\text { Sudan (Gadarif, Red Sea, Sinnar, } \\
\text { Blue Nile, and South Kordofan). }\end{array}$ \\
\hline
\end{tabular}

Sanders 2020 Piloting a TT patient caseet al [17] searching approach in Gadarif state
- $\quad$ Out of 22,548 individuals included, prevalence of TT was $(0.4 \%$ to $6.4 \%)$ in children less than 9 years, and was $(0.1 \%$ to $4.4 \%$ ) in those aged 15 years and older.

- $\quad$ Out of 66,526 residents examined, local case finders suspected that 491 residents had TT. Of them, 369 were confirmed for TT and needed surgical intervention.

- $\quad$ TT case-finding approach provides an example of an effective method for identifying TT patients 


\section{Discussion}

Most of the patients in this case series were females aging more than 50 years who have low socioeconomic status and poor personal and environmental hygiene. The majority of the patients were aged more than 50 years old, which is unlike another study in a Gambian village that showed trachoma to be found mainly in children [18]. The percentage of females patients is greater than males, this is expected and can be explained by the fact that mothers are the caregivers and are in close proximity with the reservoir of trachoma which is children less than 15 years old making them at a higher risk to get infected with trachoma. And this result is similar to other studies [19].

We observed that most of the patients in this series came for complaints other than trachoma and were diagnosed with trachoma accidentally. This is explainable because doctors think that trachoma is not common nowadays, especially in Khartoum state. This misconception affects the determination of the actual magnitude of trachoma.

With regard to socioeconomic status, most of the respondents were having poor socioeconomic status. Poor socioeconomic status is associated with poor housing and crowdedness, resulting in an increased risk of developing and transmitting the infection [7, 20]. Some of the respondents $(18.4 \%)$ reported the presence of a person infected with trachoma in the family. Studies showed the clustering nature of the disease at the community, household, and bedroom levels, reflecting the dynamics of transmission between family members with prolonged close contact [21-22]. However, patients may not be aware if someone in his family members carrying trachoma silently, which could underestimate the disease burden and delay seeking treatment.

Regarding personal hygiene, most of the respondents have poor personal hygiene in term of facial cleanliness and hands washing. Facial cleanliness is the third issue in the WHO-SAFE strategy and it was addressed by many studies [6,23-25]. The dirty face is defined by the presence of ocular and/or nasal discharge [6].

Most of the respondents have poor environmental hygiene. Many studies reported that as the distance to the water supply is increased, the prevalence of trachoma is increased [26], and other studies proved that the quantity of water used for washing faces is more important than the distance to water [27]. More than half of the respondents have animals and $86.8 \%$ of them have animals inside their houses. The animal's feces are good media for flies to accumulate, flies being considered as a vector for Chlamydia trachomatis. This is expected and proved by so many other studies [28]. Most of the respondents $(73.6 \%)$ have pit latrines inside the houses as a type of toilet, making it also a suitable environment for flies [4-6]

\section{Conclusion}


Low socioeconomic status and poor personal and environmental hygiene are common sociodemographic and household characteristics among patients with trachoma. Lack of the awareness may aid in underestimation of the actual magnitude of trachoma. Our review highlights the magnitude of trachoma and the progress towards its elimination in Sudan.

\section{List Of Abbreviations}

WHO: World Health Organization;

TF: Trachomatous inflammation - Follicular

Tl; Trachomatous inflammation - Intense

TS: Trachoma scarring

CO: Corneal opacification

\section{Declarations}

\section{Ethical approval and consent to participate:}

Permission for conducting this research was granted from the Faculty of Medicine, University of Khartoum before study initiation, and permission was also granted by the general directors of Makah Eye Complex and Abdalfadeel-Almaz hospital, Khartoum, Sudan. Ethical approval was obtained from the State Ministry of Health in Khartoum state, Sudan. Each patient's informed consent was obtained before participation in the study.

\section{Consent to publish}

not applicable.

\section{Availability of data and materials:}

The dataset generated during this study are available from the corresponding author on reasonable request.

\section{Competing interests}

The authors declare that they have no competing interests. 


\section{Funding}

No fund

\section{Authors contribution}

$(\mathrm{RH})$ undertook the conception of the research idea and data collection; (FS, HM) involved in study design and questionnaire development and supervised the whole research process; (RH, MA, RH, and SM) interpreted the results and drafted the manuscript. All authors revised and approved the final manuscript.

\section{Acknowledgments:}

Non to acknowledge.

\section{References}

1. Dick A. Clinical Ophthalmic Pathology.: John Harry, Gary Misson. Pp 376; pound125. Oxford: Butterworth-Heinemann, 2001 ISBN 075062171 0. British journal of ophthalmology. 2002;:487\&\#8211.

2. World Health Organization. Report of the 2nd Global Scientific Meeting on Trachoma, available from https://www.who.int/trachoma/resources/who_pbd_get_03.1/en/.

3. World Health Organization. http://www.who.int/mediacentre/factsheets/fs382/en/.

4. $10.1371 /$ journal.pntd. 0002513

Ramesh A, Kovats S, Haslam D, Schmidt E, Gilbert CE. The Impact of Climatic Risk Factors on the Prevalence, Distribution, and Severity of Acute and Chronic Trachoma. Johansson MA, ed. PLoS Neglected Tropical Diseases. 2013;7(11):e2513. doi:10.1371/ journal.pntd.0002513.

5. Emerson PM, Lindsay SW, Alexander N, et al. Role of flies and provision of latrines in trachoma control: cluster-randomised controlled trial. Lancet. 2004 Apr 3;363(9415):1093-8.

6. Taylor HR, Velasco FM, Sommer A. The ecology of trachoma: an epidemiological study in southern Mexico. Bull World Health Organ. 1985;63(3):559-67.

7. Hu VH, Harding-Esch EM, Burton MJ, Bailey RL, Kadimpeul J, Mabey DCW. Epidemiology and control of trachoma: systematic review. Tropical Medicine \&International Health. 2010;15(6):673-91. doi:10.1111/j.1365-3156.2010.02521.x.

8. global magnitude of a preventable cause of blindness Trachoma Mariotti SP, Pascolini D, Rose-Nussbaumer J. Trachoma: global magnitude of a preventable cause of blindness. 
9. Rushood AA, Azmat S, Shariq M, Khamis A, Lakho KA, Jadoon MZ, Sial N, Kamil EA. Ocular disorders among schoolchildren in Khartoum State, Sudan. Eastern Mediterranean health journal = La revue de sante de la Mediterraneeorientale = al-Majallah al-sihhiyah li-sharq al-mutawassit, 2013: 193, $282-8$.

10. IN MEDICAL CAMPS AT DARFUR, SUDAN

Islam LCQ, Khan A, Noor M, Malik S. (2012). MAGNITUDE OF TRACHOMA IN MEDICAL CAMPS AT DARFUR, SUDAN. Pakistan Armed Forces Medical Journal, 62(2), 237 - 40. Retrieved from https://www.pafmj.org/index.php/PAFMJ/article/view/1699.

11. Hassan A, Ngondi JM, King JD, Elshafie BE, Ginaid GA, et al. The Prevalence of Blinding Trachoma in Northern States of Sudan. PLoS Negl Trop Dis. 2011;5(5):e1027. doi:10.1371/journal.pntd.0001027.

12. Trachoma Mapping Project)

10.1080/09286586.2016.1243718

Elshafie BE, Osman KH, Macleod C, Hassan A, Bush S, Dejene M, Willis R, Chu B. Paul Courtright \& Anthony W. Solomon (for the Global Trachoma Mapping Project) (2016) The Epidemiology of Trachoma in Darfur States and Khartoum State, Sudan: Results of 32 Population-Based Prevalence Surveys, Ophthalmic Epidemiology, 23:6, 381-391, DOI: 10.1080/09286586.2016.1243718.

13. Alkhidir AAl, Wafa Ibrahim Elhag WI. Prevalence of Trachoma and Molecular detection of Chlamydia trachomatis among children in Tabldiya village, Gadarif State-Sudan. Applied Biology in Saharan Areas 2018. Vol. 2, N. 2, p. 1-9.

14. Sanders AM, Abdalla Z, Elshafie BE, Nute AW, Long EF, Aziz N, et al. Prevalence of trachoma within refugee camps serving South Sudanese refugees in White Nile State, Sudan: Results from population-based surveys. PLoS Negl Trop Dis. 2019;13(6):e0007491. https://doi.org/10.1371/journal.pntd.0007491.

15. Colin K, Macleod KH, Binnawi BE, Elshafie HE, Sadig A, Hassan, et al. for the Global Trachoma Mapping Project. Unimproved water sources and open defecation are associated with active trachoma in children in internally displaced persons camps in the Darfur States of Sudan. Trans $\mathrm{R}$ Soc Trop Med Hyg. 2019;113:599-609. doi:10.1093/trstmh/trz042.

16. Angelia M, Sanders Z, Abdalla BE, Elshafie M, Elsanosi AW, Nute N, Aziz E, Kelly Callahan SD. Progress toward Elimination of Trachoma as a Public Health Problem in Seven Localities in the Republic of Sudan: Results from Population-Based SurveysAm. J Trop Med Hyg. 2019;101(6):1296302.

17. Angelia M, Sanders M, Adam N, Aziz E, Kelly Callaha BE, Elshafie. Piloting a trachomatous trichiasis patient case-searching approach in two localities of Sudan. Trans R Soc Trop Med Hyg. 2020;00:15. doi:10.1093/trstmh/traa022.

18. Bailey R, et al. Trachoma and water use ; a case control study in a Gambian village. Trans R soc Trop Med Hyg. 1991 Nov-Dec;85(6):824-8.

19. Emerson PM, Rotondo L. Trachoma and women: latrines in Ethiopia and surgery in Southern Sudan. Community Eye Health. 2009;22(70):24-5.

20. 10.1371/journal.pntd.0001585 
Edwards T, Smith J, Sturrock HJW, et al Prevalence of Trachoma in Unity State, South Sudan: Results from a Large-Scale Population-Based Survey and Potential Implications for Further Surveys. Ngondi JM, ed. PLoS Neglected Tropical Diseases. 2012;6(4):e1585. doi:10.1371/journal.pntd.0001585.

21. Burton MJ, Holland MJ, Faal N, et al. Which members of a community need antibiotics to control trachoma? Conjunctival Chlamydia trachomatis infection load in Gambian villages.Invest Ophthalmology Vis Sci. 2003 Oct;44(10):4215-22.

22. 10.1371 /journal.pntd. 0000401

Blake IM, Burton MJ, Bailey RL, et al Estimating Household and Community Transmission of Ocular Chlamydia trachomatis. Lietman TM, ed. PLoS Neglected Tropical Diseases. 2009;3(3):e401. doi:10.1371/journal.pntd.0000401.

23. 10.1371 / journal.pntd.0002900

Last AR, Burr SE, Weiss HA, et al Risk Factors for Active Trachoma and Ocular Chlamydia trachomatis Infection in Treatment-Naïve Trachoma- Hyperendemic Communities of the Bijagós Archipelago, Guinea Bissau. Schachter J, ed. PLoS Neglected Tropical Diseases. 2014;8(6):e2900. doi:10.1371/ journal.pntd.0002900.

24. Ejere HO, Alhassan MB, Rabiu M. Face washing promotion for preventing active trachoma. Cochrane Database Syst Rev. 2012;4:CD003659. doi:10.1002/14651858.CD003659.pub3.

25. 10.1371/journal.pntd.0000973

Smith JL, Haddad D, Polack S, et al Mapping the Global Distribution of Trachoma: Why an Updated Atlas Is Needed. Lammie PJ, ed. PLoS Neglected Tropical Diseases. 2011;5(6):e973. doi:10.1371/journal.pntd.0000973.

26. 10.1371/journal.pntd. 0000583

Hägi M, Schémann J-F, Mauny F, et al Active Trachoma among Children in Mali: Clustering and Environmental Risk Factors. Gyapong JO, ed. PLoS Neglected Tropical Diseases. 2010;4(1):e583. doi:10.1371/journal.pntd.0000583.

27. Kupka K, Nižetič B, Reinhards J. Sampling studies on the epidemiology and control of trachoma in southern Morocco. Bull World Health Organ. 1968;39(4):547-66.

28. 10.1371/journal.pntd.0000799

Clements ACA, Kur LW, Gatpan G, et al Targeting Trachoma Control through Risk Mapping: The Example of Southern Sudan. Small PLC, ed. PLoS Neglected Tropical Diseases. 2010;4(8):e799. doi:10.1371/journal.pntd.0000799. 